\title{
Elena Cuasante Fernández (a cura di), Littérature d'enfance et de jeunesse
}

\section{Ilaria Vitali}

\section{(2) OpenEdition}

1 Journals

\section{Edizione digitale}

URL: https://journals.openedition.org/studifrancesi/4830

DOI: $10.4000 /$ studifrancesi.4830

ISSN: 2421-5856

\section{Editore}

Rosenberg \& Sellier

\section{Edizione cartacea}

Data di pubblicazione: 1 avril 2012

Paginazione: 191

ISSN: 0039-2944

\section{Notizia bibliografica digitale}

Ilaria Vitali, «Elena Cuasante Fernández (a cura di), Littérature d'enfance et de jeunesse», Studi Francesi [Online], 166 (I | LVI) | 2012, online dal 30 novembre 2015, consultato il 19 novembre 2021. URL: http:// journals.openedition.org/studifrancesi/4830 ; DOI: https://doi.org/10.4000/studifrancesi.4830

Questo documento è stato generato automaticamente il 19 novembre 2021.

\section{(c) $(1) \&$}

Studi Francesi è distribuita con Licenza Creative Commons Attribuzione - Non commerciale - Non opere derivate 4.0 Internazionale. 
Elena Cuasante Fernández (a cura di), Littérature d'enfance et de jeunesse

Ilaria Vitali 
NOTIZIA

ELENA CUASANTE FERNÁNDEZ (a cura di), Littérature d'enfance et de jeunesse, «Francofonía», 18, 2009, pp. 317.

1 Secondo le parole espresse da Jean Perrot in un convegno del 1993, «la seule définition réaliste d'un livre d'enfant, aussi absurde que cela semble, est la suivante: c'est un livre qui apparaît dans le catalogue d'un éditeur pour la jeunesse». È dunque sotto il segno di questa definizione, aperta e chiusa al tempo stesso, che la rivista spagnola «Francofonía» dedica un numero alla narrativa francofona per bambini e ragazzi.

Gli interventi spaziano dalla storia dell'edizione (Rachel Deroy-Ringuette) al complesso fenomeno della ricezione (Juilie Bergeron-Proulx; Sylvie Rosienski-Pellerin), passando per l'analisi dell'immagine del ragazzo nei libri a lui espressamente dedicati (Françoise Demougin). Ne emerge un quadro quanto mai ricco, interessante non solo per gli specialisti di letteratura per l'infanzia, ma per gli studiosi di francofonia e postcolonialismo in generale. Sono molte le realtà geografiche e letterarie toccate in questo numero tematico, dal Canada (Laurent PoliQuin; Eva Pich Ponce), al Marocco (Khalid RIZK), alla Réunion (Maryvette Balcou), fino all'Africa in generale (Jean-Rémi Amaoké D'Almeida). Molti sono anche i generi letterari affrontati, da quelli più tradizionalmente associati alla letteratura per ragazzi, come i contes de fée (Cecilia Fernández Santomé), fino a quelli di più recente creazione, come la bande dessinée (Faustin Nyangezi Rwamfizi). Segue il dossier tematico una miscellanea di articoli di sicuro interesse e originalità, tra cui si segnala in particolare il contributo di Carlos Alvarado-Larroucau sulle «précieuses argentines». Chiude il numero la consueta sezione di recensioni. 